\title{
A cross section of autosomal recessive limb-girdle muscular dystrophies in 38 families
}

Pervin Dinçer, Zuhal Akçören, Ercan Demir, Isabelle Richard, Özgür Sancak, Gülsev Kale, Şencan Özme, Ayşe Karaduman, Ersin Tan, J Andoni Urtizberea, Jacques S Beckmann, Haluk Topaloğlu

Department of Medical Biology, Hacettepe University Medical School, 06100 Ankara, Turkey P Dinçer

Ö Sancak

Department of Paediatric Pathology, Hacettepe University Medical School, 06100 Ankara, Turkey

Z Akçören

G Kale

Department of Paediatric Neurology, Hacettepe University Medical School, 06100 Ankara, Turkey

E Demir

A Karaduman

H Topaloğlu

Genethon, 1 rue de l'Internationale, 91002 Evry Cedex, France

I Richard

J S Beckman

Department of Paediatric Cardiology, Hacettepe University Medical School, 06100 Ankara, Turkey S Özme

Department of Neurology, Hacettepe University Medical School, 06100 Ankara, Turkey

E Tan

Institute de Myologie AFM7, Groupe Hospitalier Pitié-Salpetriére, 47-83 Boulevard de 1'Hopital, 75651 Paris Cedex 13, France

J A Urtizberea

Correspondence to: Dr Topaloğlu, National Institutes of Health, NINDS, DMNB, Building 10, Room 3D 03, 10 Center Drive, Bethesda, MD 20892-1260, USA,

htopalog@codon.nih.gov

Revised version received 1 December 1999 Accepted for publication 14 December 1999
Abstract

Limb-girdle muscular dystrophies constitute a broad range of clinical and genetic entities. We have evaluated 38 autosomal recessive limb-girdle muscular dystrophy (LGMD2) families by linkage analysis for the known loci of LGMD2A-F and protein studies using immunofluorescence and western blotting of the sarcoglycan complex. One index case in each family was investigated thoroughly. The age of onset and the current ages were between $1 \frac{1}{2}$ and 15 years and 6 and 36 years, respectively. The classification of families was as follows: calpainopathy 7 , dysferlinopathy 3 , $\alpha$ sarcoglycan deficiency $2, \beta$ sarcoglycan deficiency $7, \gamma$ sarcoglycan deficiency $5, \delta$ sarcoglycan deficiency 1 , and merosinopathy 2 . There were two families showing an Emery-Dreifuss phenotype and nine showing no linkage to the LGMD2A-F loci, and they had preserved sarcoglycans.

$\gamma$ sarcoglycan deficiency seems to be the most severe group as a whole, whereas dysferlinopathy is the mildest. Interfamilial variation was not uncommon. Cardiomyopathy was not present in any of the families. In sarcoglycan deficiencies, sarcoglycans other than the primary ones may also be considerably reduced; however, this may not be reflected in the phenotype. Many cases of primary $\gamma$ sarcoglycan deficiency showed normal or only mildly abnormal $\delta$ sarcoglycan staining.

(F Med Genet 2000;37:361-367)

Keywords: limb-girdle muscular dystrophy; genetic linkage analysis; sarcolemmal complex proteins

The limb-girdle muscular dystrophies (LGMD) are quite heterogeneous disorders. As a result of advances in clinical nosology with the aid of molecular genetics, different gene loci have been described. Most forms are autosomal recessive and the accepted nomenclature is LGMD2, whereas the dominant forms are designated LGMD $1 .^{12}$ Clinically they are characterised by symmetrical weakness of the pelvic, scapular, and trunk muscles, raised serum creatine kinase, and a necroticregenerative pattern of muscle. ${ }^{3}$ The symptoms usually begin during the first two decades of life, with the disease then gradually worsening, often resulting in loss of walking ability 10 to 20 years after onset.
Recently, loci for eight different diseases have been identified: 15q15 (LGMD2A), ${ }^{45}$ which is a muscle specific calpain-3 (CAPN3) deficiency; a dysferlinopathy on $2 \mathrm{p}^{6-8}$; the four sarcoglycanopathies in which the abnormal proteins have been identified as $\alpha$ sarcoglycan (SG) on $17 \mathrm{q} 12$ (LGMD2D), ${ }^{910} \beta-S G$ on $4 \mathrm{q} 12$ (LGMD2E), ${ }^{112} \quad \gamma$-SG on $13 \mathrm{q} 12$ (LGMD2C), ${ }^{13-16}$ and $\delta$-SG on $5 \mathrm{q} 33$ (LGMD2F). ${ }^{17-19}$ The two most recently mapped ones do not cause disruption of the SG complex and are LGMD2G on $17 \mathrm{q} 11-12^{20}$ and LGMD2H on $9 \mathrm{q} 31-33 .^{21}$ There is also an adult onset form of merosinopathy, ${ }^{22}$ an allelic form of a recessive condition that causes at least half of congenital muscular dystrophies of very early onset in life. ${ }^{23}$ Among the above described conditions, the four SG deficiencies cause disruption of the SG complex as these five proteins are closely associated in the sarcolemma. ${ }^{24-26}$ Although the issue is not entirely clear, most recent studies suggest that caveolin-3 deficiency may show autosomal dominant or recessive inheritance. ${ }^{27}$

Although some forms are known to have a relatively benign course, such as LGMD2B, ${ }^{28}$ there is no general consensus on the other LGMD2s as the fully worked up number of affected cases are limited and the severity varies in different series. We originally reported our experience in 20 families with 33 cases that we had evaluated between January 1989 and December $1995 .^{29}$ Since then, we have collected a new cohort of 41 families with 65 cases fitting the description of LGMD2, up to July 1998. Here we report the clinical, genetic, and molecular findings in 38 of these families in the light of new developments in the area. All families are Turkish. A combined approach of genetic linkage analysis with protein data comprising immunofluorescence (IF) and western blotting were used to classify families into further groups. We have mutational data on three of these families and two of them were included in our previous series. ${ }^{29}$ We intentionally included them here for the reasons stated below.

\section{Material and methods}

PATIENTS

Hacettepe University Children's Hospital in Ankara is a major referral centre for neuromuscular disorders in Turkey. Our selection criteria, which we have modified from our previous publication, ${ }^{29}$ were as follows: (1) a pedigree clearly compatible with autosomal recessive inheritance, (2) onset after the child had 
started to walk, (3) progression of muscle weakness of varying severity showing a limbgirdle distribution with sparing of facial and ocular muscles, (4) a muscle biopsy typically compatible with a muscular dystrophy, and (5) normal dystrophin and emerin immunohistochemistry in the biopsies.

Although it may be difficult to classify the severity of the disease, as the time between the onset of symptoms and the rate of evolution may be short at times, the following parameters are chosen for practical purposes for grading the functional stage of dystrophy in a mainly paediatric setting: (1) severe, if onset was in childhood and the disability was similar to Duchenne muscular dystrophy (DMD), (2) intermediate, if onset was in childhood and the progression or disability was like Becker muscular dystrophy (BMD), (3) moderate, if onset was in adulthood and the patient showed physical disability of any grade, and (4) benign, if onset was in adulthood and the patient did not have any disability (able to run freely, but some weakness, less than grade I). ${ }^{30}$ The classification of DMD and BMD was taken from Dubowitz, ${ }^{31}$ that is, a child who becomes unable to walk before the age of 13 is registered as DMD-like, and one that is still ambulant after the age of 16 is registered as BMD-like.

There were 18 multiplex families. Consanguinity was present in 39 of 41 families. The study was carried out in 38 families in whom genetic linkage analysis and protein data showed correlation. Twenty of the 38 index cases were girls. Only one index case was studied clinically per family. The age at onset of symptoms was between $1 \frac{1 / 2}{2}$ and 15 years. The ages at the time of biopsy varied between $2 \frac{1}{2}$ and 21 years. The serum creatine kinase levels were at least five times higher than normal. Duration of follow up was between 1 and 11 years.

CARDIAC EVALUATION

Chest $x$ ray and routine EKG recordings were obtained twice yearly. Cardiac echograms, which were performed in 33 index cases, were normal.

\section{MUSCLE BIOPSY}

Muscle biopsies were performed after informed consent using standard open biopsy techniques under local anaesthesia by two of us (ED and HT). One family refused muscle biopsy, but they gave consent for DNA studies. Samples were snap frozen in isopentane, cooled, and stored in liquid nitrogen until processed. Frozen blocks were also used for western blotting.

Six serial micron sections cut using a cryostat were stained for routine histology by haematoxylin-eosin and modified Gomoritrichrome along with a battery of histochemical reactions. IF studies were done for the following: spectrin (NCL-SPEC1®), dystrophin (NCL-DYS $1 \AA$, DYS $2 \AA$ and DYS $3 \AA)$, alpha-SG (NCL-50DAG $\left.{ }^{\circledR}\right)$, beta-SG (NCL43DAG $\left.{ }^{\circledR}\right)$, gamma-SG (NCL-35DAG $\left.{ }^{\circledR}\right)$, delta-SG (NCL-35DAG $\left.{ }^{\circledR}\right)$, laminin $\alpha 2$ chain
(NCL-MEROSIN $\left.{ }^{\circledR}\right)$, and emerin (NCL-

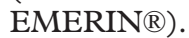

IMMUNOBLOTS

Immunoblot analyses were performed in 37 patients as described by Piccolo et $a l^{10}$ and also by using a multiplex system of different antibodies (for example, Dys2, $\alpha$, and $\gamma$ antibodies are used for hybridisation of one membrane whereas Dys $1, \beta$, and $\delta$ antibodies are used for the hybridisation of the other in the same patient) as described by Anderson and Davison. ${ }^{32}$

The primary antibodies were the same for immunofluorescence. Additional $\beta$ and $\gamma$-SG antibodies were kindly provided by K Campbell, Iowa, USA.

GENOTYPING, LINKAGE STUDIES, AND MUTATIONS DNA was obtained from peripheral blood after signed consent of the individual family members. Highly polymorphic markers of chromosomes 2p13-p16，4q12，5q33-q34，13q12, $15 \mathrm{q} 15.1-\mathrm{q} 15.3$, and $17 \mathrm{q} 12-\mathrm{q} 21.33$ were used for analysing the 38 LGMD2 families. The fluorescent labelled markers for LGMD2A, LGMD2B, LGMD2C, LGMD2D, LGMD2E, and LGMD2F patients were arranged in three different groups (2A with $2 \mathrm{~B}$, $2 \mathrm{C}$ with $2 \mathrm{D}, 2 \mathrm{E}$ with $2 \mathrm{~F}$ ), so that all of the markers could be tested together in a multiplex system. ${ }^{33}$ All of the 41 families, except two, were consanguineous and linkage was ascertained by homozygosity by descent (HBD). ${ }^{34}$ In inbred populations such as ours, this method has been proven to be very fruitful; however, in the absence of consanguinity the same yield may not be obtained. In three of the families linkage analysis was not sufficient to identify the chromosome responsible. Thus, these families were not included in this paper. The closest markers used for each locus were as follows. Markers for LGMD2A: 070xd7, 806G4G10-d, 854f9b4, 944b11-d, 265xf9-d; markers for LGMD2B: a343xe9, 203xc3, a205zc5, a296xc5; markers for LGMD2C: D13S232, a217yb5, 351xd9-d, c021xe1; markers for LGMD2D: CA-ADL, a351we1, 234td2, 269zb1-d, 269xd1; markers for LGMD2E: 168xa5, 274xb9, CA12T, b359yh9; and markers for LGMD2F: 336xe9, 329tf5, 191xd8-t. ${ }^{35}$ Mutations of $\gamma$ and $\delta$ sarcoglycans have been published ${ }^{29}$ and submitted elsewhere (Dinçer et al, submitted).

\section{Results}

The vast majority of our families were closely consanguineous. We put our LGMD2 families following the immunohistochemistry, western blotting, and linkage analysis data into alphabetical order, that is, from LGMD2A to LGMD2F, and taking into consideration the physical stigmata and protein studies of the Emery-Dreifuss phenotype. As we have not genotyped our families for the $\mathrm{G}$ and $\mathrm{H}$ loci yet, we have classified the rest as "others". The SG complex was preserved in the calpainopathy, dysferlinopathy, merosinopathy, EmeryDreifuss phenotype, and "other" groups. A summary of the clinical features of our series is 
Table 1 Clinical features of index cases with LGMD2

\begin{tabular}{|c|c|c|c|c|c|c|c|c|}
\hline Cases & $\begin{array}{l}\text { Age at onset } \\
\text { (y) }\end{array}$ & Sex & $\begin{array}{l}\text { Family } \\
\text { history }\end{array}$ & $\begin{array}{l}\text { Age walked } \\
\text { (y) }\end{array}$ & Scapular w & Calves & $\begin{array}{l}C K \\
(\times N)\end{array}$ & Evolution \\
\hline \multicolumn{9}{|c|}{ Calpainopathy } \\
\hline 1 & $16(10)$ & $\mathrm{F}$ & + & 1 & + & - & 30 & Intermediate \\
\hline 2 & $17(12)$ & $\mathrm{F}$ & + & 2 & - & + & 32 & Moderate \\
\hline 3 & $37(12)$ & M & + & $1 \frac{1 / 2}{2}$ & + & - & 21 & Moderate \\
\hline 4 & $17(8)$ & $\mathrm{F}$ & - & 1 & + & - & 18 & Intermediate/moderate \\
\hline 5 & $11(7)$ & $\mathrm{M}$ & + & 1 & + & + & 23 & Intermediate/moderate \\
\hline 6 & $17(11)$ & M & - & $1 \frac{1 / 2}{2}$ & - & - & 9 & Intermediate \\
\hline 7 & $19(11)$ & $\mathrm{F}$ & - & 1 & + & - & 10 & Moderate \\
\hline \multicolumn{9}{|c|}{ Dysferlinopathy } \\
\hline 8 & $18(15)$ & $\mathrm{M}$ & + & 1 & - & + & 40 & Moderate \\
\hline 9 & $13(10)$ & M & - & 3 & - & - & 25 & Moderate* \\
\hline 10 & $21(15)$ & $\mathrm{F}$ & + & $1 \frac{1 / 2}{2}$ & - & - & 23 & Moderate \\
\hline \multicolumn{9}{|c|}{$\begin{array}{l}\text { Sarcoglycanopathy } \\
\alpha \text { sarcoglycan deficiency }\end{array}$} \\
\hline 11 & $14(11)$ & $\mathrm{F}$ & - & 1 & - & - & 12 & Intermediate \\
\hline 12 & $10(6)$ & $\mathrm{M}$ & - & 1 & - & + & 17 & Severe \\
\hline \multicolumn{9}{|c|}{$\beta$ sarcoglycan deficiency } \\
\hline 13 & $\left(8^{1 / 2}\right)$ & $\mathrm{F}$ & - & 1 & + & + & 32 & Intermediate \\
\hline 14 & $24(14)$ & $\mathrm{F}$ & + & 1 & + & + & 20 & Moderate \\
\hline 15 & $29(14)$ & $\mathrm{F}$ & + & 1 & + & + & 11 & Moderate \\
\hline 16 & $8(2)$ & $\mathrm{F}$ & - & $1 \frac{1 / 2}{2}$ & - & + & 8 & Intermediate \\
\hline 17 & $13(6)$ & $\mathrm{M}$ & + & 1 & - & - & 8 & Intermediate \\
\hline 18 & $19(13)$ & $\mathrm{M}$ & - & 1 & + & + & 6 & Moderate \\
\hline 19 & $12(2)$ & $\mathrm{F}$ & - & 1 & - & + & 23 & Intermediate \\
\hline \multicolumn{9}{|c|}{$\gamma$ sarcoglycan deficiency } \\
\hline 20 & $6(3)$ & M & - & 1 & - & + & 16 & Intermediate \\
\hline 21 & $10(3)$ & $\mathrm{F}$ & - & $31 / 2$ & - & - & 65 & Severe \\
\hline 22 & $11(7)$ & M & + & 1 & - & + & 23 & Intermediate \\
\hline $23+$ & $20(7)$ & $\mathrm{F}$ & - & $1 \frac{1 / 2}{2}$ & - & + & 39 & Severe \\
\hline $24 \dagger$ & $14(6)$ & $\mathrm{F}$ & + & $1^{1 / 2}$ & - & + & 16 & Severe \\
\hline \multicolumn{9}{|c|}{$\delta$ sarcoglycan deficiency } \\
\hline $25+$ & $14(8)$ & $\mathrm{F}$ & - & $11 / 2$ & - & - & 58 & Severe \\
\hline \multicolumn{9}{|c|}{ Merosinopathy } \\
\hline 26 & $8(11 / 2)$ & $\mathrm{F}$ & + & 1 & - & - & 5 & Intermediate \\
\hline 27 & $8(2)$ & $\mathrm{F}$ & - & $1^{1 / 2}$ & - & - & 4 & Intermediate \\
\hline \multicolumn{9}{|c|}{ Emery-Dreifuss phenotype } \\
\hline 28 & $12(3)$ & $\mathrm{F}$ & - & 2 & - & - & 9 & Intermediate \\
\hline 29 & $17(10)$ & M & + & 1 & - & - & 18 & Intermediate/moderate \\
\hline \multicolumn{9}{|l|}{ Others } \\
\hline 30 & $20(6)$ & M & + & 3 & - & - & 16 & Intermediate/moderate \\
\hline 31 & $36(17)$ & M & - & 1 & - & + & 25 & Benign \\
\hline 32 & $17(2)$ & $\mathrm{M}$ & - & 1 & - & - & 11 & Intermediate/moderate \\
\hline 33 & $17(5)$ & M & - & 5 & - & - & 18 & Intermediate/moderate \\
\hline 34 & $20(6)$ & $\mathrm{M}$ & + & 2 & - & - & 20 & Severe \\
\hline 35 & $26(15)$ & M & + & $1^{1 / 2}$ & - & - & 17 & Moderate \\
\hline 36 & $8(2)$ & M & + & $1 \frac{1 / 2}{2}$ & - & - & 18 & Intermediate \\
\hline 37 & $15(6)$ & $\mathrm{F}$ & + & $2^{1 / 2}$ & - & + & 6 & Intermediate \\
\hline 38 & $14(7)$ & $\mathrm{F}$ & - & $1 \frac{1 / 2}{2}$ & + & + & 20 & Intermediate \\
\hline
\end{tabular}

Scapular w: scapular winging.

*Also has ataxia telangiectasia.

$\nmid$ Mutation studies completed.

presented in table 1. Cardiomyopathy was not found in any of our cases. In general, interfamilial variability of symptoms was a common finding in most groups.

GROUP 1: CALPAINOPATHY

There were seven index cases in this group, with ages varying between 11 and 37 . They all have an intermediate to moderate clinical course so far. There were three patients with a delayed walking age of $11 / 2$ and 2 years. The 37 year old patient comes from a large pedigree where one distant cousin is homozygously affected. Interestingly, this patient has a heterozygous haplotype (data not shown), with mild symptoms and a raised CK of $1400 \mathrm{U} / 1$. Scapular winging was present in five cases and calf hypertrophy was seen to a mild degree in two of the older patients, but generally it was of atrophic type with the hamstrings being more wasted.

GROUP 2: DYSFERLINOPATHY

There were three families in this group. The patients' ages are between 13 and 21. One patient had walked late at the age of 3 years. This patient also has ataxia telangiectasia. One of them shows distal features such as muscle wasting, fitting into the Miyoshi phenotype. All cases typically have moderate to benign courses. Mild calf hypertrophy was present in one case.

GROUP 3: SARCOGLYCANOPATHY

This group could be divided into four subgroups.

\section{a-SG deficiency}

The ages of two patients belonging to this group are 10 and 14 years. The 10 year old boy with an onset of 6 years has become unable to walk within 4 years, thus presenting a severe DMD-like picture that includes pseudohypertrophy of the calves and thighs. The other patient has an intermediate to moderate course with unremarkable features. Protein data in both cases showed reduction of the other three SGs as well as the primary one, with the severe case having more reduction of $\alpha$-SG (table 2 ).

$\beta-S G$ deficiency

There are seven families in this group, with the ages of index cases varying between 8 and 29 years. One of the cases walked late. All cases 
Table 2 Properties of sarcoglycans in sarcoglycanopathies

\begin{tabular}{|c|c|c|c|c|c|}
\hline Case & $a-S G$ & $\beta-S G$ & $\gamma-S G$ & $\delta-S G$ & $\begin{array}{l}\text { Age, clinical } \\
\text { stage }\end{array}$ \\
\hline \multicolumn{6}{|c|}{$\alpha$ sarcoglycan deficiency } \\
\hline 11 & ++ & +++ & +++ & ++ & $14, \mathrm{I}$ \\
\hline 12 & 0 & + & 0 & + & $10, \mathrm{VI}$ \\
\hline \multicolumn{6}{|c|}{$\beta$ sarcoglycan deficiency } \\
\hline 13 & ++ & +++ & + & +++ & $13, \mathrm{II}$ \\
\hline 14 & +++ & N.D. & ++ & N.D. & $24, \mathrm{II}$ \\
\hline 15 & N.D. & N.D. & N.D. & N.D. & 29, II \\
\hline 16 & ++ & 0 & +++ & +++ & $8, \mathrm{I}$ \\
\hline 17 & ++ & ++ & + & ++ & $13, \mathrm{II}$ \\
\hline 18 & ++ & +++ & +++ & 0 & $19, \mathrm{II}$ \\
\hline 19 & ++ & +++ & +++ & +++ & $12, \mathrm{I}$ \\
\hline \multicolumn{6}{|c|}{$\gamma$ sarcoglycan deficiency } \\
\hline 20 & ++ & ++ & 0 & $\mathrm{~N}$ & $6, \mathrm{II}$ \\
\hline 21 & +++ & + & +++ & $\mathrm{N}(+)$ & $10, \mathrm{III}$ \\
\hline 22 & + & + & +++ & $\mathrm{N}$ & $11, \mathrm{II}$ \\
\hline $23^{\star}$ & + & $\mathrm{N}$ & +++ & $\mathrm{N}$ & $20, \mathrm{IV}$ \\
\hline $24^{\star}$ & +++ & ++ & 0 & $\mathrm{~N}(+)$ & $14, \mathrm{IV}$ \\
\hline \multicolumn{6}{|c|}{$\delta$ sarcoglycan deficiency } \\
\hline $25^{\star}$ & 0 & +++ & 0 & 0 & $14, \mathrm{VI}$ \\
\hline
\end{tabular}

show intermediate to moderate clinical courses. The oldest patient in this group, a 29 year old female, is only moderately affected and has a 4 year old unaffected daughter (fig 1). Her evolution is the mildest in this particular family, but other affected members of the family were more severe, again to a varying degree. Scapular winging and prominent calves were present in four and six cases, respectively. Again, all SGs showed various degrees of reduction in each individual case with $\beta-S G$ being severely reduced or zero.

\section{$\gamma-S G$ deficiency}

This group shows a rapidly progressive evolution. Among the five patients with ages between 6 and 20 years, there are two cases with intermediate and three cases with severe evolution. One case started walking at $31 / 2$ years and in two others walking was delayed at $1 \frac{1}{2}$ years. Four patients have calf hypertrophy and none has scapular weakness. Protein studies showed reduction of $\alpha, \beta$, and $\gamma$ SGs with $\gamma$-SG being the most degraded one; however, $\delta$-SG was preserved or mildly reduced in these patients (table 2). This was true for both linkage $(n=3)$ and mutation proven $(n=2)$ cases. We intentionally took the latter cases in this series to "double-check" this correlation. Both patients had a homozygous 923-924 del TG mutation. $^{29}$

\section{$\delta$-SG deficiency}

We have one patient in this group. She definitely has a severe DMD-like course with onset at the age of 8 and then becoming wheelchair bound by the age of 12 . All her SGs are severely reduced. There is no cardiomyopathy. Mutation data show that she has a stop codon in exon 3 (Dinçer et al, submitted).

\section{Merosinopathy}

The two girls in this group aged 8 and 6 years had onset at 1 year and 18 months, respectively. Both cases walked before 18 months of age. They are both ambulant with mild motor handicap, so are classified as intermediate to moderate. We have been following them for six and two years, respectively, and there has been no worsening of symptoms. Laminin $\alpha 2$ chain is mildly reduced in IF studies against the 80 $\mathrm{kDa}$ portion of the protein, the classical antibody. They both have typical white matter changes on cranial MRI scans confirming merosin deficiency.

\section{OTHERS}

Emery-Dreifuss phenotype

Both families presented with somewhat distal features, such as Achilles tendon shortening, elbow contractures, and rigid spine to a mild degree.

Immunostaining against emerin antibodies was normal. One of the index cases was a 12 year old girl.

\section{Remaining cases}

We have a total of nine families with typical proximal weakness showing a limb-girdle distribution for which we could not find the locus responsible.

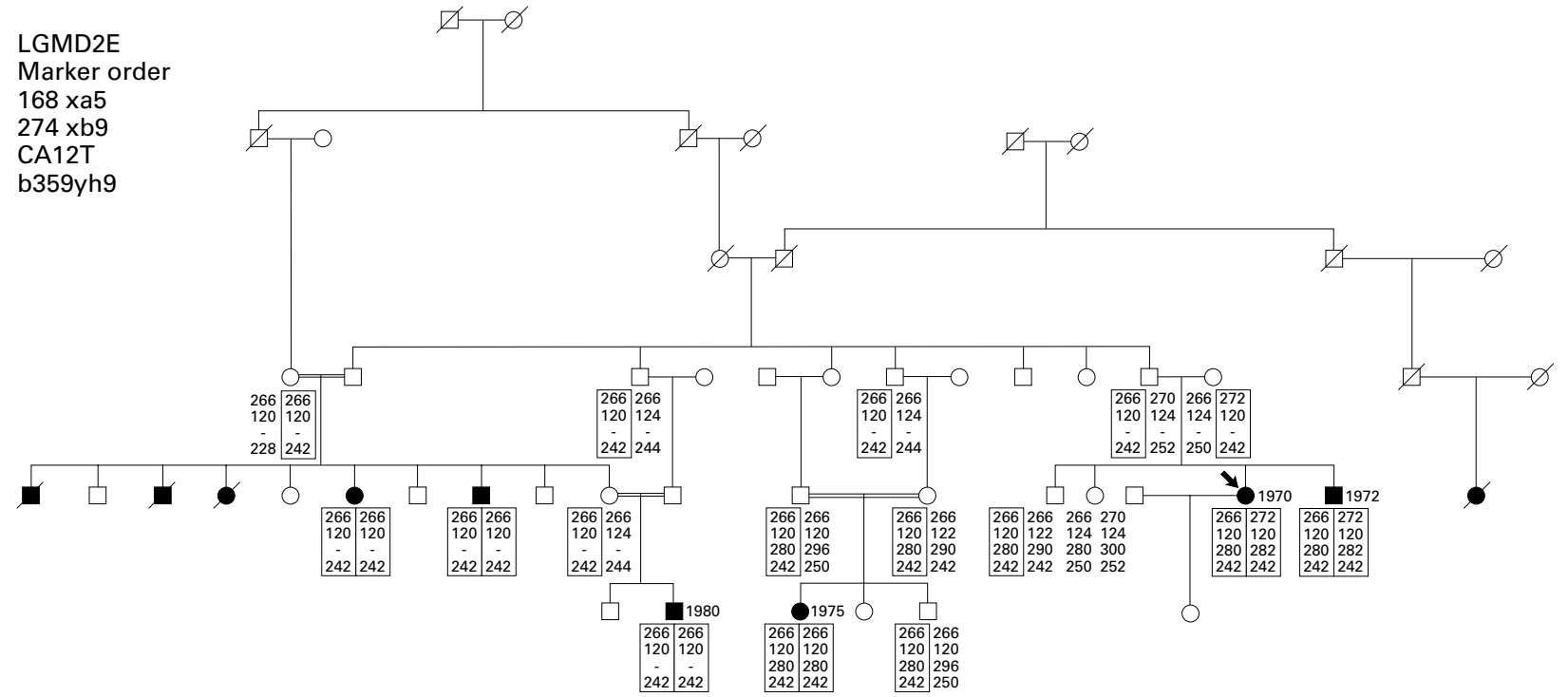

Figure 1 Pedigree of a family with LGMD2E (family 15). 
In four families linkage by homozygosity by descent was to the LGMD2F region. We further screened the gene and did not find any mutations. All sarcoglycans were preserved in all four, unlike the case in $\delta$ sarcoglycan deficiency. This suggests linkage by chance because of smaller family sizes. Three patients, despite relatively early onsets of 2 and $5 \frac{1}{2}$ years, are very mild clinically and could be considered as intermediate to moderate. The oldest case of our series is now 36 years old and belongs to this latter group. This case has been reported twice before elsewhere. ${ }^{29}{ }^{36} \mathrm{He}$ is the only one in our series with a quite benign course.

The remainder are five families with the index cases being between 8 and 26 years old. None of them showed any distal features. Linkage analysis excluded all the known loci from LGMD2A to F.

\section{Discussion}

We have identified several subgroups in our country where consanguineous marriages are frequent. ${ }^{37}$ Our aim was not to make a phenotype/genotype correlation, but to give a cross section of different subgroups within LGMD2.

The prevalence of LGMD has been estimated to be $20-40$ per million. ${ }^{38}$ However, this figure varies in different series. In isolated populations such as Réunion, it has been found to be 48 per million ${ }^{39}$ and in the Basque country the figure is as high as 69 per million. ${ }^{40}$ The high rate of inbreeding and the number of multiplex families $(n=18)$ may result in the relatively high number of cases in our setting. So far, with our previous publication, ${ }^{29}$ we have documented 98 cases from 61 families. However, we cannot give a prevalence, because of the fact that ours is mainly a paediatric setting, and also there may be other patients who are still undiagnosed. In any case, our data differ from those of isolated communities because, unlike these, such as calpainopathy being more prevalent in Réunion and the Basque country, clusters of $\beta$-SG deficiency in the Amish, ${ }^{11}$ or $\gamma$-SG deficiency in the Gypsy population of Europe ${ }^{41}$ we have detected LGMD2 patients of varying subgroups including five unlinked families.

In general, our protein studies, IF and western blotting, gave parallel results and linkage analysis correlated with them. We were able to assign the disease in our families, who were usually large, to particular chromosomes. In the clinic, our patients showed that inter- and intrafamilial variation is common in all subgroups. In the light of previous reports and combining our data, we would like to discuss and highlight basic characteristics of LGMD2 as follows.

\section{CALPAINOPATHY}

Calpain-3 deficiencies are usually moderate, though there may be exceptions. In the original families from the Réunion Islands, about 50\% of patients lost ambulation around the age of 20 , as was true in patients described in Lebanon. ${ }^{42}$ However, in the subsequent large series from metropolitan France, cases were milder. ${ }^{39}$ This has also been our previous ${ }^{43}$ and current experience. Urtasun $e t a l^{40}$ did not find specific correlations between the nature and site of the mutation and the resulting phenotype. The general consensus is that patients carrying two null mutations have a more homogeneous course and can be relatively severe, whereas two missense or compound heterozygous mutations have a broad range of evolution. ${ }^{33}$ A typical appearance for calpainopathy would be generalised atrophy, scapular winging, and relatively selective involvement of the hamstring muscles compared to the anterior compartment of the thighs. This phenotype was seen in the majority of our patients and was present in one case as early as 11 years.

\section{DYSFERLINOPATHY}

So far, all the reported cases in this subgroup have moderate courses, including the distal Miyoshi type. ${ }^{44}{ }^{45}$ We have also experienced the same in our cases from previous and current series. This entity can even have a true onset after puberty. One of our cases had somewhat distal features suggesting a Miyoshi phenotype. Despite mild clinical courses, all our cases had greatly increased CK levels, 23-40 times higher than normal values.

\section{SARCOGLYCANOPATHIES}

We know from mutation analysis that missense mutations are usually associated with a milder phenotype while truncating mutations tend to produce a more severe course. ${ }^{1011}{ }^{13}$ However, clear exceptions to this generalisation have been seen. ${ }^{46-49}$

\section{$\alpha$-SG DEFICIENCY}

Primary $\alpha$-SG deficiency is clinically heterogeneous, the severity of the disease varies strikingly, and correlates in part with the type of mutation and the amount of residual protein. ${ }^{46}$ In our two cases, the severe one who lost ambulation within four years after onset at 6 years of age had zero $\alpha-S G$ in the protein studies, whereas the milder case had only reduced levels of protein.

\section{$\beta$-SG DEFICIENCY}

Patients belonging to this group may also be severe or mild. Calf hypertrophy may be present. There are Amish patients who are still ambulant in the fifth decade. In the original Amish series by Lim et $a l,{ }^{11}$ the clinical onset was at 7.6 years (range 4 to 12) and loss of walking at 26 years (range 12 to 38 years), with marked interfamilial variability. All seven cases in our group have either intermediate or moderate clinical courses so far. On the other hand, the only case from our previous report had a severe outcome. Onset was at 12 years and she lost ambulation by the age of $20 .^{29}$ As a whole, all SGs show substantial reductions in the biopsies. It is interesting to note that, despite SG loss, patients could have mild to moderate clinical courses at least to their current ages, in our experience the oldest being 24 . 
$\gamma$-SG DEFICIENCY

This probably constitutes the most severe of all the sarcoglycan deficiencies. In this group, the majority of patients were severely affected. The two intermediate of our cases were younger than 11 years of age, so their prognosis may also be severe in due course. $\gamma$-SG was severely reduced or zero as has been well documented. ${ }^{45}{ }^{46}$ In the series of Vainzof et $a l^{45}$ there was a complete absence of $\gamma-S G$. Interestingly, in their cases, $\delta$-SG seems to be the most preserved, as detected in our series, probably indicating that $\gamma-\mathrm{SG}$ is loosely associated with $\delta$-SG in the sarcolemmal membrane. Thus, the retention of some of the SG components should not be considered prognostic for a milder phenotype.

\section{$\delta$-SG DEFICIENCY}

The patient has a stop codon mutation, has complete absence of the SG complex, and presents with a severe phenotype. All the reported cases within this group similarly have severe evolution. ${ }^{1845}$

\section{MEROSINOPATHY}

We previously described the original patient with late onset merosin deficiency. ${ }^{22}$ Abnormalities of merosin (laminin $\alpha 2$ chain) normally result in a very severe congenital onset muscular dystrophy, but its allelic variant, the $300 \mathrm{kDa}$ portion of the laminin $\alpha 2$ chain is missing or reduced. ${ }^{23}$ The two patients we have had walked at 1 and $1 \frac{1 / 2}{2}$ years, respectively. This is far beyond the clinical description of classical merosin deficiency, in which patients must have symptoms before the age of 6 months. Also, they both had typical MRI changes in the white matter. These patients with merosin deficiency once again remind us that this latter condition should also be included in the differential diagnosis of LGMD2.

\section{EMERY-DREIFUSS PHENOTYPE}

Typical EDMD is an $\mathrm{X}$ linked disorder. ${ }^{50}$ However, there is also an autosomal dominant form..$^{51}$ This is located at the locus described in three families identified as having autosomal dominant limb-girdle muscular dystrophy with cardiac involvement. ${ }^{52}$ Also, Bethlem myopathy may be a mimicking condition..$^{53}$ The typical clinical stigmata are of distal findings such as contracture of the elbows and Achilles tendons with rigidity of the neck muscles in some cases. In the $\mathrm{X}$ linked form patients develop cardiomyopathy after their teens. With the presence of consanguinity, our two families suggest autosomal recessive inheritance. However, further analyses are needed.

\section{OTHERS}

There are occasional LGMD families where no linkage to any of the known chromosomal loci has been found. We have nine families with this condition except that linkage studies for the most recently described loci of LGMD2G and $\mathrm{H}$ have not been performed. They all have preserved SGs and the classical features of proximal and progressive weakness. It is unlikely that any of these families could be linked to the LGMD2G locus, as this condition is mostly distal. ${ }^{20}$ So far, LGMD2H has been reported only in Hutterites in Manitoba and presents with a relatively mild muscular dystrophy. ${ }^{21}$ As caveolin-3 deficiency may be autosomal recessive in some families, this must be checked in our remaining series. ${ }^{27}$

So far, our genetic linkage analysis and protein data have shown good correlation, that is, all our unlinked families have normal sarcoglycans, and all cases with reduced sarcoglycan were linked to a specific sarcoglycan locus. Mutation studies are under way.

To summarise our findings, there is extreme heterogeneity in the clinical presentation and some patients have delayed onset of walking. Interfamilial variation is not uncommon. Scapular winging and selective wasting of the hamstrings is peculiar to calpainopathy. All cases of dysferlinopathy have a milder evolution. Calf hypertrophy is a cardinal feature of sarcoglycan deficiencies. $\gamma$-SG deficiency seems to be the most severe group. Cardiomyopathy was not encountered in our series. As far as the protein studies are concerned, this may help to distinguish the gene responsible. At the $\beta$-SG locus all SGs are reduced; however, in the clinic not necessarily all patients are severe. In $\gamma$-SG deficiency, $\gamma$-SG is always severely reduced or zero at the locus, but $\delta$-SG is normal or only mildly abnormal. Finally $\delta$-sarcoglycan deficiency causes almost complete disarray of the complex.

We are grateful to our muscular dystrophy families who have fully participated in this project. This study was partially funded by a grant from the TUBITAK (SBAG-1774). We would like to thank the Association Française contre les Myopathies (AFM), France for continuous support. We thank Carsten Bönneman, University of Göttingen who did the mutation analysis in the $\gamma$ and $\delta$-sarcoglycan genes. We would like to acknowledge Genethon, France for their skilful technical assistance. The International Atomic Energy Agency (IAEA) has also contributed to the project.

1 Walton JN, Nattrass FJ. On the classification, natural history and treatment of the myopathies. Brain 1954;77:169-231. and treatment of the myopathies. Brain 1954;77:169-231.

ENMC international workshop-the limb-girdle muscular ENMC international workshop-the limb-girdle muscular
dystrophies, and proposal for a new nomenclature.

3 Bushby KMD. Limb-girdle muscular dystrophy. In: Emery AEH, ed. Diagnostic criteria for neuromuscular disorders. Baarn, The Netherlands: ENMC, 1994:25-31.

4 Beckmann JS, Richard I, Hillaire D, et al. A gene for limb-girdle muscular dystrophy maps to chromosome 15 by linkage. C R Acad Sci 1991;312:141-8.

5 Richard I, Broux O, Allamand V, et al. Mutations in the proteolytic enzyme calpain 3 cause limb-girdle muscular dystrophy type 2A. Cell 1995;81:27-40.

6 Bashir R, Strachan T, Keers S, et al. A gene for autosomal recessive limb-girdle muscular dystrophy maps to chromosome 2p. Hum Mol Genet 1994;3:455-7.

7 Liu J, Aoki M, Illa I, et al. Dysferlin, a novel skeletal muscle gene, is mutated in Miyoshi myopathy and limb girdle gene, is mutated in Miyoshi myopathy and

8 Bashir R, Britton S, Strachan T, et al. A gene related to Caenorhabditis elegans spermatogenesis factor fer- 1 is mutated in limb-girdle muscular dystrophy type 2B. Nat Genet 1998;20:37-42.

9 Roberds SL, Leturcq F, Allamand V, et al. Missense mutations in the adhalin gene linked to autosomal recessive muscular dystrophy. Cell 1994;78:625-33.

10 Piccolo F, Roberds SL, Jeanpierre M, et al. Primary adhalinopathy: a common cause of autosomal recessive muscular dystrophy of variable severity. Nat Genet 1995;10: 243-5.

11 Lim LE, Duclos F, Broux O, et al. $\beta$-sarcoglycan: characterization and role in limb-girdle muscular dystrophy linked to 4q12. Nat Genet 1995;11:257-65.

12 Bönneman CG, Modi R, Noguchi S, et al. $\beta$-sarcoglycan (A3b) mutations cause autosomal recessive muscular
dystrophy with loss of the sarcoglycan complex. Nat Genet 1995;11:266-73. 
13 Noguchi S, McNally EM, Ben Othmane K, et al. Mutations in the dystrophin-associated protein $\gamma$-sarcoglycan in chro-

14 Azibi K, Bachner L, Beckmann JS, et al. Severe childhood Azibi K, Bachner L, Beckmann JS, et al. Severe childhood
autosomal recessive muscular dystrophy with the defiautosomal recessive muscular dystrophy with the defimaps to chromosome 13q12. Hum Mol Genet 1993;2:14238.

15 Ben Othmane K, Ben Hamida M, Pericak-Vance MA, et al. Linkage of Tunisian autosomal recessive Duchenne-like muscular dystrophy to the pericentromeric region of chromosome 13q. Nat Genet 1992;2:315-17.

16 Jung D, Leturcq F, Sunada Y, et al. Absence of $\gamma$-sarcoglycan (35 DAG) in autosomal recessive muscular dystrophy linked to chromosome 13q12. FEBS Lett 1996;381:15-20.

17 Passos-Bueno MR, Moreira ES, Vainzof M, Marie SK, Zatz M. Linkage analysis in autosomal recessive limb-girdle
muscular dystrophy (AR LGMD) maps a sixth form to muscular dystrophy (AR LGMD) maps a sixth form to
$5 \mathrm{q} 33-34$ (LGMD2F) and indicates that there is at least one more subtype of AR LGMD. Hum Mol Genet 1996;5:81520 .

18 Nigro V, Moreira ES, Piluso G, et al. Autosomal recessive limb-girdle muscular dystrophy, LGMD2F, is caused by a mutation in the $\delta$-sarcoglycan gene. Nat Genet 1996;14 $195-8$

19 Nigro V, Belsito A, Politano L, et al. Identification of a novel sarcoglycan gene at $5 \mathrm{q} 33$ encoding a sarcolemmal $35 \mathrm{kD}$ glycoprotein. Hum Mol Genet 1996;5:1179-86.

20 Moreira ES, Vainzof M, Marie SK, Sertie AL, Zatz M, Passos-Bueno MR. The seventh form of autosoma recessive limb-girdle muscular dystrophy is mapped to 17q11-12. Am Ұ् Hum Genet 1997;61:151-9.

21 Weiler T, Greenberg CR, Zelinski T, et al. A gene for autosomal recessive limb-girdle muscular dystrophy in Manitoba Hutterites maps to chromosome 9q31-33: evidence for another limb-girdle muscular dystrophy. Am $\mathcal{F}$ Hum Genet 1998;63:140-7.

22 Tan E, Topaloğlu H, Sewry C, et al. Late onset muscular dystrophy with cerebral white matter changes due to partial dystrophy with cerebral white matter changes due to
merosin deficiency. Neuromusc Disord 1997;7:85-9.

23 Hillaire D, Leclerc A, Faure S, et al. Localization of merosin-negative congenital muscular dystrophy to chromosome $6 \mathrm{q} 2$ by homozygosity mapping. Hum $\mathrm{Mol}$ Genet 1994;3:1657-61.

24 Topaloğlu H, Kale G, Yalnizoğlu D, et al. Analysis of "pure" congenital muscular dystrophies in thirty-eight cases. How different is the classical type 1 from the occidental type cerebromuscular dystrophy? Neuropediatrics 1994;25:94-100

25 Worton R. Muscular dystrophies: diseases of the dystrophin-glycoprotein complex. Science 1995;270:755-7.

26 Emery A. The muscular dystrophies. BMF 1998;317:991-5.

27 Kunkel L. Caveolin-3 deficiency as a cause of limb-girdle muscular dystrophy. $\mathcal{F}$ Child Neurol 1999;14:33-4.

28 Mahineh, I, Passos-Bueno MR, Zatz M, et al. The phenotype of chromosome $2 \mathrm{p}$-linked limb-girdle muscular phenotype of chromosome 2p-linked limb-gird
dystrophy. Neuromusc Disord 1996;6:483-90.

29 Dincer P, Leturcq F, Richard I, et al. A biochemical, genetic and clinical survey of autosomal recessive limb girdle muscular dystrophies in Turkey. Ann Neurol 1997;42:222-9.

30 Gardner-Medwin D, Walton JN. The clinical examination of the voluntary muscles. In: Walton JN, ed. Disorders of voluntary muscles. 3rd ed. Edinburgh: Churchill Living voluntary muscles.

31 Dubowitz V. Muscle disorders in childhood. London: Saunders, 1995:39-45

32 Anderson LVB, Davison K. Multiplex western blotting system for the analysis of muscular dystrophy proteins. Am $f$ Pathol 1999;154:1017-22.

33 Richard I, Bourg N, Marchand S, et al. A diagnostic fluorescent marker kit for six limb girdle muscular dystrophies. Neuromusc Disord (in press).
34 Lander ES, Botstein D. Homozygosity mapping: a way to map human recessive traits with the DNA of inbred children. Science 1987;236:1567-70.

35 Dib C, Faure S, Fizames C, et al. A comprehensive genetic map of the human genome based on 5,264 microsatellites. Nature 1996;380:152-4.

36 Topaloğlu H, Tan E, Dinçer P, Erdem S, Akçören Z. Good clinical observation is essential before molecular studies. Lancet 1995;346:1490.

37 Tunçbilek E, Koç I. Consanguineous marriage in Turkey and its impact on fertility and mortality. Ann Hum Genet 1994;58:321-9.

38 Emery AEH. Population frequencies of inherited neuromuscular diseases: a world survey. Neuromusc Disord 1991; $1: 19-29$.

39 Fardeau M, Hillaire D, Mignard C, et al. Juvenile limb-girdle muscular dystrophy. Clinical, histopathological and genetic data from a small community living in the Reunion Island. Brain 1996;119:295-308.

40 Urtasun M, Saenz A, Roudaut C, et al. A limb-girdle muscular dystrophy in Guipuzcoa (Basque Country, Spain). Brain 1998;121:1735-40.

41 Piccolo F, Jeanpierre MJ, Leturcq F, et al. A founder mutation in the $\gamma$-sarcoglycan gene of Gypsies possibly predating their migration out of India. Hum Mol Genet 1996;5:2019-22.

42 Richard I, Brenguier L, Dinçer P, et al. Multiple independent molecular etiology for LGMD2A patients from various geographic origins. Am f Hum Genet 1997;60:1128-38.

43 Topaloglu H, Dinçer P, Richard I, et al. Calpain-3 defciency causes a mild muscular dystrophy in childhood. Neuropediatrics 1997;28:212-16.

44 Bashir R, Keers S, Strachan T, et al. Genetic and physical mapping at the limb-girdle muscular dystrophy locus (LGMD2B) on chromosome 2p. Genomics 1996;33:46-52.

45 Vainzof M, Passos-Bueno MR, Canovas $M$, et al. The sarcoglycan complex in the six autosomal recessive limb-girdle muscular dystrophies. Hum Mol Genet 1996;5: 1963-9.

46 Jeanpierre M, Carrie A, Piccolo F, et al. From adhalinopathies to alpha-sarcoglycanopathies. Neuromusc Disord 1996; 6:463-5.

47 McNally EM, Passos-Bueno MR, Bönnemann CG, et al. Mild and severe muscular dystrophy caused by a single $\gamma$-sarcoglycan mutation. Am f Hum Genet 1996;59:1040-7.

48 Ben Hamida M, Ben Hamida C, Zouari M, Belal S, Hentati F. Limb-girdle muscular dystrophy 2C: clinical aspects. Neuromusc Disord 1996;6:493-4.

49 Ozawa E, Noguchi S, Mizuno Y, Hagiwara Y, Yoshida M. From dystrophinopathy to sarcoglycanopathy: evolution of a concept of muscular dystrophy. Muscle Nerve 1998;21: 421-38.

50 Emery AE. Emery-Dreifuss syndrome. $7 \mathrm{Med}$ Genet $1989 \cdot 26: 637-41$

51 Bonne G, Di Barletta MR, Varnous S, et al. Mutations in the gene encoding lamin $\mathrm{A} / \mathrm{C}$ cause autosomal dominant Emery-Dreifuss muscular dystrophy. Nat Genet 1999;21: 285-8.

52 van der Kooi AJ, van Meegen M, Ledderhof TM, McNally EM, de Visser M, Bolhuis PA. Genetic localization of a newly recognized autosomal dominant limb girdle muscular dystrophy with cardiac involvement (LGMD1B) to chromosome 1q11-21. Am f Hum Genet 1997;60:891-5.

53 Jobsis GJ, Keizers H, Vreijing JP, et al. Type VI collagen mutations in Bethlem myopathy, an autosomal dominant myopathy with contractures. Nat Genet 1996;14:113-15. 